\title{
HIGHER ANNUAL OPERATOR VOLUME IS ASSOCIATED WITH BETTER REPERFUSION RATES IN STROKE PATIENTS TREATED BY MECHANICAL THROMBECTOMY IN THE ETIS REGISTRY
}

Rody EL NAWAR ${ }^{1,2}$; Bertrand LAPERGUE ${ }^{3,4}$; Michel PIOTIN ${ }^{5}$; Benjamin GORY ${ }^{6}$; Raphael BLANC ${ }^{5}$; Arturo CONSOLI $^{7}$; Georges $\mathrm{RODESCH}^{7}$; Mikael MAZIGHI ${ }^{5}$; Frederic BOURDAIN ${ }^{3}$; Maéva KYHENG ${ }^{8}$, Julien LABREUCHE ${ }^{8}$, Fernando PICO ${ }^{1,4}$ on behalf ETIS Investigators

1- Department of Neurology and Stroke Center, Centre Hospitalier de Versailles, Versailles, France

2- Gilbert and Rose-Marie Chagoury School of Medicine, Lebanese American University, Beirut, Lebanon

Email : roudynawar@hotmail.com

3- Department of Neurology and Stroke Center, Hopital Foch, Suresnes, France

4- Université Versailles Saint-Quentin en Yvelines et Paris Saclay

5- Department of Interventional Neuroradiology, Rothschild Foundation, Paris, France

6- Department of Diagnostic and Interventional Neuroradiology, Hospices Civils de Lyon, Lyon, France

7- Department of Diagnostic and Interventional Neuroradiology, Hopital Foch, Suresnes, France

8- Univ. Lille, CHU Lille, EA 2694 - Santé publique: épidémiologie et qualité des soins, F-59000 Lille, France

Background and Purpose: Mechanical thrombectomy (MT) is a level IA treatment in the acute phase of ischemic stroke (IS) ${ }^{1}$. The operator's effect have been found to be an independent predictor of the outcome in interventional cardiology for STEMI syndromes ${ }^{2,4}$. The aim of this study was to analyse if operator characteristics have an impact on reperfusion and complications rates.

Methods: From the ETIS study, a prospective, multicenter, observational real world MT registry, we included 1541 IS patients consecutively treated by MT between January 2012 and March 2017 in 3 high volume MT centers by 19 operators. We assessed the effect of individual operator on successful reperfusion (defined as a modified thrombolysis in cerebral infarction (2b/3)) and procedural complications (acquired new embolic territory infarction, arterial perforation and dissection) using a multivariable hierarchical logistic regression models.

Table 1. Relationship between annual operator volume (categorized in 3 levels) and successful reperfusion after thrombectomy (mTICl 2b/3)

\begin{tabular}{|c|c|c|c|c|c|}
\hline & \multirow[b]{2}{*}{$\begin{array}{c}\text { Operator } \\
\text { (n) }\end{array}$} & \multicolumn{2}{|c|}{ Successful Reperfusion } & \multirow{2}{*}{$\begin{array}{c}\text { Adjusted OR } \\
(95 \% \mathrm{Cl})\end{array}$} & \multirow[b]{2}{*}{$\begin{array}{l}\text { P- } \\
\text { value }\end{array}$} \\
\hline & & No $(n=359)$ & Yes $(n=1175)$ & & \\
\hline MT/year & & & & & $0.003^{\star}$ \\
\hline$<14$ & 6 & $55(15.3)$ & $87(7.4)$ & 1.00 (ref) & - \\
\hline 14-39 & 7 & $219(61.0)$ & $691(58.8)$ & $1.75(1.02-2.99)$ & 0.040 \\
\hline$\geq 40$ & 6 & $85(23.7)$ & $397(33.8)$ & $2.52(1.37$ to 4.64$)$ & 0.003 \\
\hline
\end{tabular}

Successful reperfusion was defined as amTICI $2 \mathrm{~b} / \mathrm{c}$ at the end of endovascular procedure. $\mathrm{OR}$ and $\mathrm{P}$-value calculated in multivariate hierarchical logistic regression model including patient-levels characteristics associated with successful reperfusion in univariate analyses $(\mathrm{p}<0.20)$.

${ }^{*}$ calculated by including annual al operator volume levels as an ordinal variable.

Abbreviations: OR=odds ratio; $\mathrm{MT}=$ mechanical thrombectomy; $\mathrm{mTICI}=$ modified treatment in cerebral infarction

Corresponding author: Fernando PICO, MD, PhD

FPico@ch-versailles.fr

Department of Neurology and Stroke Center,CentreHospitalier de Versailles, Versailles, France177 Rue de Versailles, 78150 Le Chesnay Université Versailles Saint-Quentin en Yvelines et Paris Saclay
Results: A total of 1541 anterior and posterior stroke patients were enrolled (mean age 67 years; median NIHSS 16). After controlling patient's characteristics, there is a significant operator effect on successful reperfusion, with an intraclass correlation coefficient (ICC) of $0.036(p=0.046))$ but not on complications $(I C C=0)$. There was a dose response relationship between annual operator volume and successful reperfusion $(p=0.003)$. Compared with patients treated by operator with annual volume $<14 \mathrm{MT}$, the adjusted odds ratio (95\% confidence interval) for successful reperfusion was 1.75 (1.02 to 2.99) for patients treated by an operator with annual volume between 14 and 39 MT and 2.52 (1.37 to 4.64$)$ for patients treated by an operator with annual volume $\geq 40 \mathrm{MT}$

Conclusions: Our data suggested that successful reperfusion in IS patients treated with MT was dependent on operator volume of MT per year.

Table 2. Relationship between annual operating volume per operator (categorized in 3 levels) and procedural complication outcome controlling for associated patient characteristics.

\begin{tabular}{lccccc}
\hline & $\begin{array}{c}\text { Operator } \\
(\mathrm{n})\end{array}$ & $\begin{array}{c}\text { No } \\
\text { complication }\end{array}$ & Complications & $\begin{array}{c}\text { Adjusted OR } \\
(95 \% \mathrm{Cl})\end{array}$ & $\begin{array}{c}\text { P- } \\
\text { value }\end{array}$ \\
\hline $\begin{array}{l}\text { Annual volume, } \\
\begin{array}{l}\text { MT/year } \\
<14\end{array}\end{array}$ & 6 & $114(9.0)$ & $24(9.7)$ & 1.00 (reference) & - \\
$14-39$ & 7 & $747(59.2)$ & $150(60.7)$ & $1.07(0.60$ to 1.89$)$ & 0.64 \\
$\geq 40$ & 6 & $401(31.8)$ & $73(29.6)$ & $0.95(0.51$ to 1.76$)$ & 0.57 \\
\hline
\end{tabular}

OR and $P$-value calculated in multivariate hierarchical logistic regression model including patient-levels characteristics associated with complication outcome in univariate analyses $(p<0.20){ }^{*}$ calculated by including annual operator volume as an ordinal variable.

References:

1- Powers, W. J., et al. "American Heart Association Stroke Council. 2015 American Heart Association/American Stroke Association focused update of the 2013 guidelines for the early management of patients with acute ischemic stroke regarding endovascular treatment: a guideline for healthcare professionals from the American Heart Association/American Stroke Association." Stroke 46.10 (2015): 3020-3035.

2- Klein, Lloyd W., et al. "Does low individual operator coronary interventional procedural volume correlate with worse institutional procedural outcome?." Journal of the American College of Cardiology 30.4 (1997): 870-877

3- Kastrati, Adnan, Franz-Josef Neumann, and Albert Schömig. "Operator volume and outcome of patients undergoing coronary stent placement." Journal of the American College of Cardiology 32.4 (1998): 970-976.

4- Reddy, V. Y., D. Holmes, and K. Shephal. "Safety of Percutaneous Left Atrial Appendage Closure: Results from the Watchman Left Atrial Appendage System for Embolic Protection in Patients With AF (PROTECT AF) Clinical Trial and the Continued Access Registry Circulation DOI: 10.1161/CIRCULATIONAHA. 110.976449." (2011). 